\title{
Correction to: A whitelist and blacklist-based co-evolutionary strategy for defensing against multifarious trust attacks
}

\author{
Shujuan $\mathrm{Ji}^{1,2} \cdot$ Haiyan $\mathrm{Ma}^{1} \cdot$ Yongquan Liang ${ }^{1} \cdot$ Hofung Leung ${ }^{3} \cdot$ Chunjin Zhang ${ }^{4}$
}

Published online: 12 May 2018

(C) The Author(s) 2018

\section{Correction to: Appl Intell (2017) 47:1115-1131 https://doi.org/10.1007/s10489-017-0944-x}

The article A whitelist and blacklist-based co-evolutionary strategy for defensing against multifarious trust attacks, written by Shujuan Ji, Haiyan Ma, Yongquan Liang, Hofung Leung and Chunjin Zhang, was originally published electronically on the publisher's internet portal (currently SpringerLink) on May 13, 2017 without open access.

With the author(s)' decision to opt for Open Choice the copyright of the article changed on May 2018 to (C) The Author(s) 2017 and the article is forthwith distributed under the terms of the Creative Commons Attribution 4.0
International License (http://creativecommons.org/licenses/ by/4.0/), which permits use, duplication, adaptation, distribution and reproduction in any medium or format, as long as you give appropriate credit to the original author(s) and the source, provide a link to the Creative Commons license and indicate if changes were made.

Open Access This article is distributed under the terms of the Creative Commons Attribution 4.0 International License (http:// creativecommons.org/licenses/by/4.0/), which permits unrestricted use, distribution, and reproduction in any medium, provided you give appropriate credit to the original author(s) and the source, provide a link to the Creative Commons license, and indicate if changes were made.
The online version of the original article can be found at https://doi.org/10.1007/s10489-017-0944-x.

Shujuan Ji

jane_ji2003@aliyun.com

1 Shandong Provincial Key Laboratory of Wisdom Mine Information Technology, Shandong University of Science and Technology, Qingdao, China

2 Shandong Provincial Key Laboratory of Novel Distributed Computer Software Technology, Shandong Normal University, Jinan, China

3 Department of Computer Science and Engineering, The Chinese University of Hong Kong, Hong Kong, China

4 Center of Network, Shandong University of Science and Technology, Qingdao, China 